\title{
Interferometric SAR monitoring of the Vallcebre landslide (Spain) using corner reflectors
}

\author{
M. Crosetto ${ }^{1}$, J. A. Gili ${ }^{2}$, O. Monserrat ${ }^{1}$, M. Cuevas-González ${ }^{1}$, J. Corominas ${ }^{2}$, and D. Serral ${ }^{2}$ \\ ${ }^{1}$ Institute of Geomatics, Parc Mediterrani de la Tecnologia, Av. Gauss 11, 08860, Castelldefels, Barcelona, Spain \\ ${ }^{2}$ Department of Geotechnical Engineering and Geosciences, Technical University of Catalonia (UPC), C/ Jordi Girona 1-3, \\ D-2 Building, 08034, Barcelona, Spain
}

Correspondence to: M. Crosetto (michele.crosetto@ideg.es)

Received: 19 December 2012 - Published in Nat. Hazards Earth Syst. Sci. Discuss.: Revised: 20 February 2013 - Accepted: 3 March 2013 - Published: 17 April 2013

\begin{abstract}
This paper describes the deformation monitoring of the Vallcebre landslide (Eastern Pyrenees, Spain) using the Differential Interferometric Synthetic Aperture Radar (DIn$\mathrm{SAR}$ ) technique and corner reflectors (CRs). The fundamental aspects of this satellite-based deformation monitoring technique are described to provide the key elements needed to fully understand and correctly interpret its results. Several technical and logistic aspects related to the use of CRs are addressed including an analysis of the suitability of DInSAR data to monitor a specific landslide, a discussion on the choice of the type of CRs, suggestions for the installation of CRs and a description of the design of a CR network. This is followed by the description of the DInSAR data analysis procedure required to derive deformation estimates starting from the main observables of the procedure, i.e., the interferometric phases. The main observation equation is analysed, discussing the role of each phase component. A detailed discussion is devoted to the phase unwrapping problem, which has a direct impact on the deformation monitoring capability. Finally, the performance of CRs for monitoring ground displacements has been tested in the Vallcebre landslide (Eastern Pyrenees, Spain). Two different periods, which provide interesting results to monitor over time the kinematics of different parts of the considered landslide unit, are analysed and described.
\end{abstract}

\section{Introduction}

This paper focuses on landslide deformation monitoring using the Differential Interferometric Synthetic Aperture
Radar (DInSAR) technique and corner reflectors (CRs). The performance of this technique is illustrated considering the deformation monitoring of an active landslide, the Vallcebre landslide (Eastern Pyrenees, Spain). The DInSAR techniques exploit the information contained in the radar phase of at least two complex SAR images acquired at different times over the same area, generating interferograms. For a general review see Rosen et al. (2000) and Crosetto et al. (2005). Many of the DInSAR results obtained in the 1990s were achieved using the standard DInSAR configuration, which in some cases is the only one that can be implemented due to limited SAR data availability. A remarkable improvement in the quality of the DInSAR results is given by the advanced DInSAR methods that use large datasets of SAR images acquired over the same deformation phenomenon, e.g., see Ferretti et al. (2000, 2001); Berardino et al. (2002); Hooper et al. (2004); Crosetto et al. (2005, 2008).

DInSAR has traditionally been used to monitor landslides (Strozzi et al., 2005, 2010; García-Davalillo et al., 2013). Furthermore, landslide processes have been successfully detected and monitored using an Advanced DInSAR technique called Persistent Scatterer Interferometry (PSI). The PSI technique provides both the intensity and the temporal evolution of the landslide movement. In this regard, relevant research on landslide monitoring by means of PSI can be found in the literature (Colesanti et al., 2003; Hilley et al., 2004; Colesanti and Wasowski, 2006; Farina et al., 2006; Meisina et al., 2006; Herrera et al., 2010; Cigna et al., 2012). Landslide monitoring using DInSAR suffers two major limitations. The first one is the lack of coherence between SAR images acquired over landslides covered by vegetation, 
which prevents the use of DInSAR. The second limitation is related to the ambiguous nature of the DInSAR observations, the interferometric phases, which is discussed later in this paper. Lack of coherence can be avoided using artificial CRs. These devices, installed in a given area of interest, provide a strong response in the SAR images resulting in good interferometric phases to derive precise deformation estimates. It is important to note that in those cases where natural reflectors are unavailable in the area, the deformation estimates are only limited to the artificial CRs deployed in the area at hand.

This paper illustrates the DInSAR monitoring using CRs of the Vallcebre landslide, an active landslide that has been studied using a wide range of monitoring techniques in the last $25 \mathrm{yr}$. The main goal of this paper is to discuss the basic aspects of CR-based DInSAR monitoring, which include technical and logistic aspects (DInSAR feasibility analysis, choice of the CRs, design of the CR network and CR installation) and the data analysis procedure required to derive deformation estimates. This procedure is discussed in detail, to provide an insight of the most relevant aspects needed to correctly understand and interpret the DInSAR deformation results. The experimental results obtained in the Vallcebre landslide are finally discussed.

\section{Study area: the Vallcebre landslide}

The Vallcebre landslide is located in the Eastern Pyrenees, approximately $125 \mathrm{~km}$ north of Barcelona, Spain. Its situation, geological context and a complete geomorphological description can be found in Corominas et al. (2005). The mobilised material consists of a set of shale, gypsum and claystone layers gliding over a thick limestone bed. The average slope of the landslide is about $10^{\circ}$. The movement affects an area of $0.8 \mathrm{~km}^{2}$, which shows superficial cracking and distinct ground displacements. The landslide is a translational slide with a stair-shape profile. Figure 1 shows a geomorphologic sketch of the landslide and the location of the monitored points and boreholes. The most active area is the lower unit, the toe of which is being eroded continuously by the Vallcebre torrent. As in most landslides, its structure and behaviour is not simple. The measurement of displacements is very often the simplest way to observe the evolution of a landslide and to analyse either the kinematics of the movement, the response to the triggering conditions (i.e., rainfall) or the efficiency of corrective measures.

Several monitoring techniques have been tested in Vallcebre since 1987. For instance, surveying and photogrammetry have been used since the beginning of the monitoring campaigns of this landslide in 1987, and GPS started in 1995. During the following years the landslide was equipped with a network of inclinometers, in-hole wire extensometers and piezometers. Moreover, in late 2006, seven artificial CRs were installed for testing the DInSAR monitoring capabilities (this technique is discussed in detail in Sect. 3). More recently, the Vallcebre landslide has been monitored using a Ground-Based SAR (GB-SAR), see Monserrat et al. (2013).

The first monitoring network established on the landslide was based on close-range photogrammetry with a total of seven campaigns performed at the landslide foot between 1987 and 1992. In general, the application of this method is not straightforward because of the difficulty of finding a proper set-up with an adequate view over the slope. Also, a dedicated and costly equipment is required. Between 1987 and 1995, geodetic measurements with theodolite and Electronic Distance Measurement (EDM) were carried out using triangulation and single distance variation, covering up to 16 points spread out through the landslide lower unit. The angle measurements were carried out with a Wild T2 theodolite and the EDM with a Wild DIOR 3002S.

GPS measurements were introduced in 1994 and, after a first test in July 1994, a complete EDM and GPS survey was carried out in December 1995 to link the measurements obtained from these techniques. A total of 27 GPS campaigns have been carried out since 1995, with Trimble (4000 SSi) and Topcon (Hiper Pro) receivers using either the static (FastStatic or Quick-Static) or kinematic (Real Time Kinematic) methods, depending on the satellite visibility of the points. In the Vallcebre site, GPS performed better than the abovementioned surveying techniques both in terms of error ellipses (they are more homogeneous in the three axes in the case of GPS) and of the measured deformation pattern. The estimated error $(1 \sigma)$ for a single GPS Fast-Static positioning is $12 \mathrm{~mm}$ in horizontal and $18 \mathrm{~mm}$ in elevation (Gili et al. 2000). New points were added since 1995 achieving a network of 50 points. Most of them are engraved in rock blocks outcropping in the hillside or the top of the casing of the inclinometric boreholes; several steel rods, stakes and poles have been used as well.

The previous network allowed measuring the displacements and comparing them with the values obtained with the borehole equipment, i.e., inclinometers and wire extensometers. Effectively, in addition to the surface equipment, in-hole techniques have been used too, allowing gaining knowledge of the underground behaviour. Between July 1996 and April 1998, 14 boreholes were drilled in the slope and equipped with inclinometers, wire extensometers, and open standpipe piezometers. In 2004-2005 multipoint piezometers were installed in three additional boreholes. This system has proven to work properly with landslide displacements much larger than those that cause the break of inclinometric pipes, see for details Corominas et al. (2000). A main advantage of the piezometers and wire extensometers is that they were installed with an automatic recording system which allowed obtaining a continuous measurement, especially needed to collect information during the concentrated rainfall periods. Using these data it was possible to identify a perfect synchronism between changes in displacements and the groundwater level inside the slope (Corominas et al., 2005). 


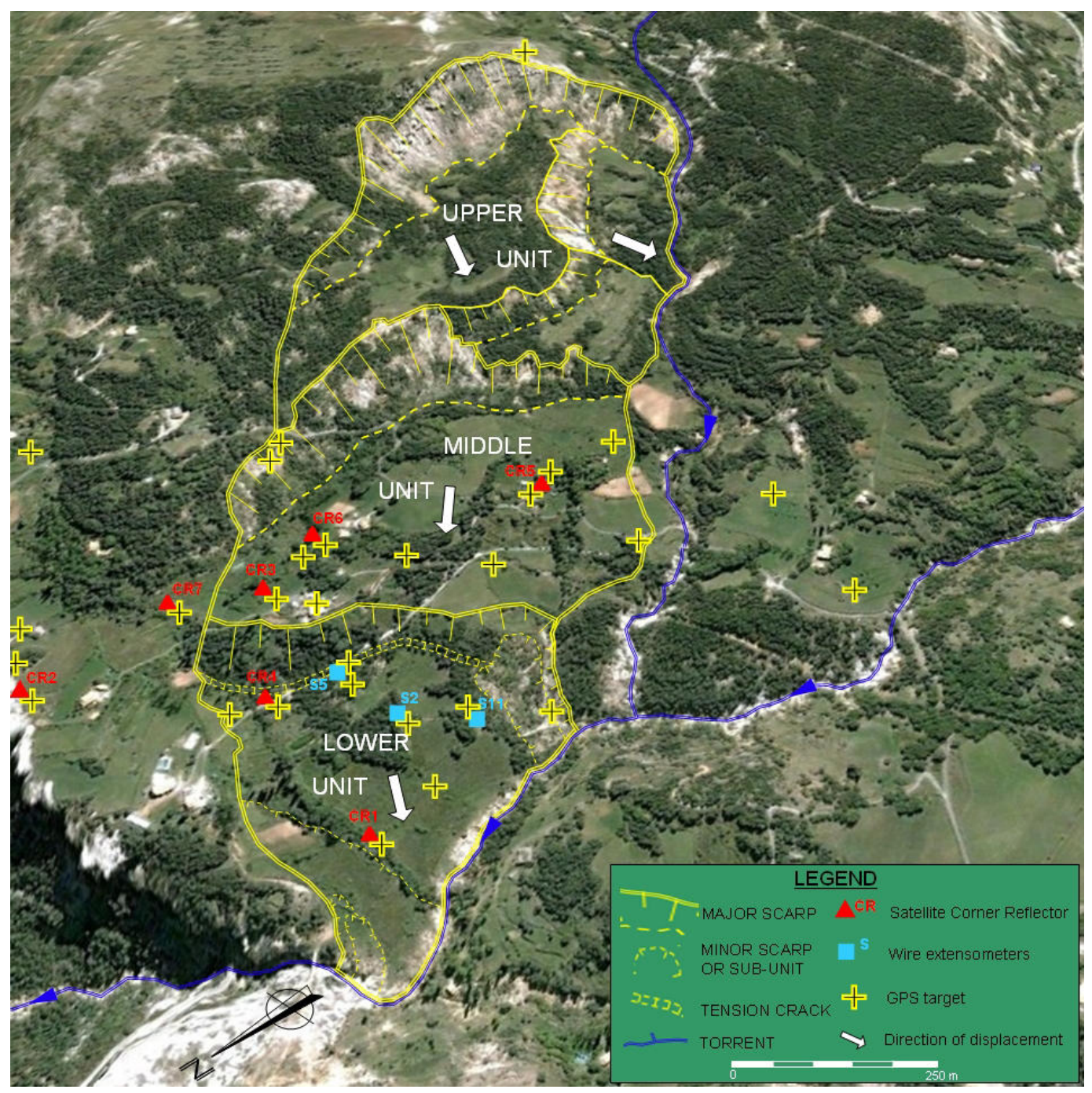

Fig. 1. Geomorphologic scheme of the Vallcebre landslide superimposed over an aerial image. The upper, middle and lower units, separated by scarps, can be appreciated. Several GPS, corner reflector and wire measuring points are marked with symbols. Image courtesy of the Institut Cartogràfic de Catalunya.

With the instrumentation described above, during the period 1987-1995, displacements as large as $8 \mathrm{~m}$ were observed at the lower unit, decreasing uphill. The movement rates were strongly dependent on the rainfall. At certain points near the toe and in the rainy years, rates of about $4 \mathrm{~m} \mathrm{yr}^{-1}$ were observed, while almost no displacement occurred during the drought periods. In the middle and upper landslide units, the rate of displacement was significantly smaller, in the range of 10 to $30 \mathrm{~cm} \mathrm{yr}^{-1}$. Additional information about the monitoring of Vallcebre can be found in Corominas et al. (2000), Gili et al. (2000) and Monserrat et al. (2013).

\section{DInSAR monitoring using corner reflectors}

This section discusses the basic technical aspects of DInSAR monitoring using CRs. The key technical and logistic aspects related to the planning and installation of CRs are analysed, followed by a description of the data analysis procedure required to derive deformation estimates from the interferometric phases.

\subsection{Corner reflectors: network design and installation}

The indispensable condition to use DInSAR is that a sufficient number of targets of the area of interest remain coherent during the observation period, i.e., maintain constant, over time, their complex reflectivity (Hanssen, 2001). This condition is often not satisfied in landslide monitoring, especially 

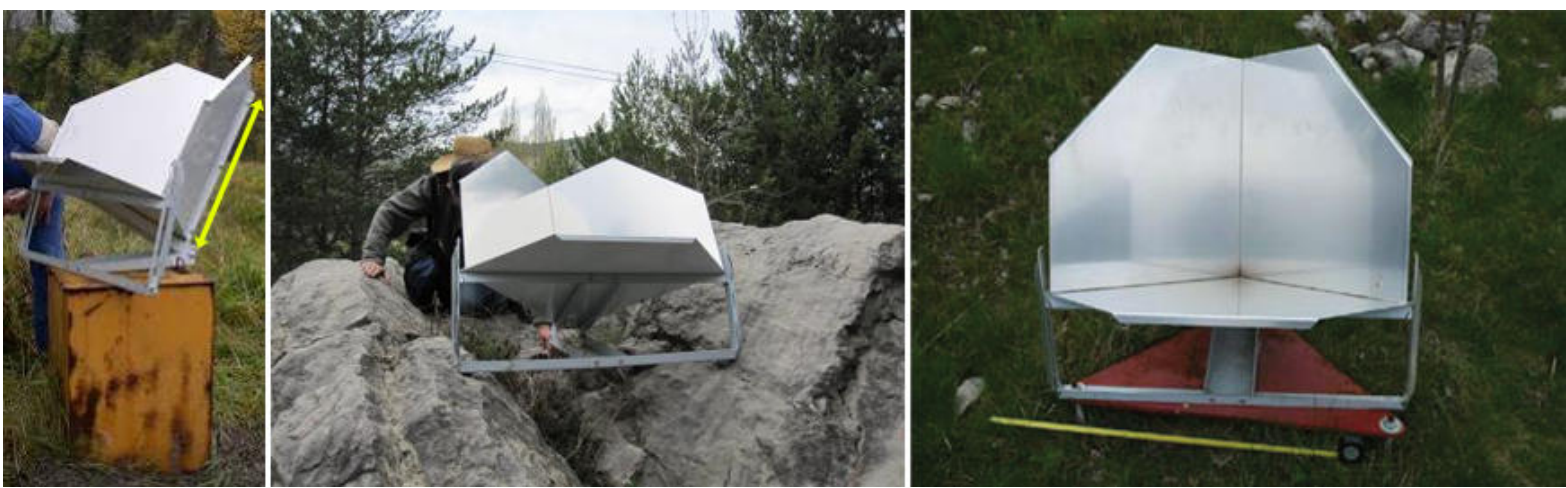

Fig. 2. Corner Reflectors (CRs) used to monitor the Vallcebre landslide. The yellow arrow indicates the size of the side of the CRs which is $67 \mathrm{~cm}$. Three types of CR installation were performed in the Vallcebre landslide: over a metallic box, on rocks or directly over the terrain.

for areas fully covered by vegetation. A way to overcome this limitation is the deployment of artificial CRs that guarantee obtaining coherent and high-quality DInSAR estimates over strategically selected locations. It is worth emphasising that there are two important differences between the classical DInSAR applications and those based on CRs. Firstly, the latter ones need the in situ installation of the CRs, requiring additional resources. Secondly, the use of CRs prevents from performing historical deformation studies based on archived SAR imagery, which represent one of the most important advantages of DInSAR, because only the SAR images acquired after the CR installation can be used. In this section, several important aspects related to the practical implementation of a network of CRs, illustrating the case of Vallcebre, are briefly discussed.

1. Suitability of DInSAR data for monitoring the landslide at hand. A preliminary step to any DInSAR-based landslide monitoring is to evaluate the capability of DInSAR to measure the landslide at hand considering in particular two geometric characteristics: slope aspect and inclination (Colesanti and Wasowski, 2006). Considering the geometry of ERS (right-side looking with an offnadir angle of $23^{\circ}$ ), the ascending SAR data are suitable for slopes facing East and with inclinations below $67^{\circ}$, while the descending data are appropriate for slopes facing West, with the same limit of $67^{\circ}$. In this regard, the slope of the Vallcebre landslide falls within the latter case. The slopes facing North or South can in principle be imaged by both ascending and descending data. However, DInSAR has a very low sensitivity to displacements along the South to North direction, which complicates the DInSAR monitoring of such slopes unless the displacement shows a significant vertical component.

2. Choice of the CRs. The CRs have to guarantee a sufficiently strong response to be clearly distinguished from other bright neighbouring targets in the amplitude SAR images and to obtain an adequate signal to noise ratio (Ferretti et al., 2007). The most common CRs are metallic trihedral corner reflectors (Doerry, 2008). In the Vallcebre landslide, metallic trihedral CRs manufactured by NPA (www.npagroup.com) were used (Fig. 2). The dimension of one side of the CR, as shown in Fig. 2 , is $67 \mathrm{~cm}$.

3. Design of the CR network. Provided that DInSAR performs relative displacement measurements and assuming that no natural reflectors are available in the area at hand, at least one pair of CRs need to be installed to estimate the relative displacement of one CR with respect to the other one, which is used as reference. In practice, a larger set of CRs is used to properly cover the landslide of interest. Two important aspects have to be considered while designing a CR network:

a. In order to keep the atmospheric component negligible, the distance between neighbouring CRs has to be kept as short as possible. It is worth recalling that the characteristics of the atmospheric component vary considerably from site to site. In order to illustrate the importance of this component in DInSAR observations, we refer to the study described in Crosetto et al. (2002). In this study, a set of C-band ERS interferograms was analysed over an urban area known to be stable, estimating the atmospheric signal between pairs of points, as a function of the distance. It was found that the standard deviation of the atmospheric component ranges, in terms of Line-Of-Sight (LOS) displacement, from 0.7 to $1.8 \mathrm{~mm}$ at $100 \mathrm{~m}$; from 0.8 to $3.1 \mathrm{~mm}$ at $200 \mathrm{~m}$; and from 0.9 to $3.6 \mathrm{~mm}$ at $300 \mathrm{~m}$. In the authors' experience the distance between CRs should be limited to a few hundreds of metres, to guarantee limited atmospheric effects at least in the estimation of the inter-CR deformation. This limitation can be even stricter in case of steep slopes, because the atmospheric variations are frequently stronger vertically than horizontally due to 
atmospheric layering. If a single reference point is used, one has to consider that the atmospheric effects are more severe for the more distant CRs. If the CR network has a considerable extension, the implementation of a proper strategy to reduce the atmospheric effects is needed. In the Vallcebre landslide the maximum distance between CRs is $300 \mathrm{~m}$.

b. A second important constraint related to the location and inter-distance of CRs is the expected kinematic characteristics of the landslide to be monitored. This issue is linked to the ambiguous nature of the DInSAR phases: the displacements can be correctly retrieved only if they cause phase differences between neighbouring pixels smaller than $\pi$ radians. In terms of displacements between two pairs of CRs, with image coordinates $(i, j)$ and $(k, l)$, this condition is:

$\mid$ Deformation_ $\Delta t(i, j)-$ Deformation_ $\Delta t(k, l) \mid<\frac{\lambda}{4}$

where $\lambda$ is the wavelength (e.g., $5.6 \mathrm{~cm}$ in C-band, and $3.1 \mathrm{~cm}$ in X-band), and Deformation $\Delta t$ is the deformation occurred in the time interval between two image acquisitions. In order to satisfy the above condition, it is necessary to properly adjust the time interval $\Delta t$ or reduce the inter-distance between CRs. For this reason, it is recommended to collect a priori information on the expected deformation rates and deformation pattern before designing a CR network. The CR inter-distance should be reduced where the expected spatial deformation gradients are bigger. If some parts of a given landslide are too fast to be measured by DInSAR (i.e., too fast to satisfy the above condition), it is recommended to avoid installing CRs on them. The Vallcebre landslide is formed by three units. The existing monitoring system has shown that landslide displacements are mostly concentrated in the intermediate and lowest units. The latter is the most active one, with cumulative displacements of several centimetres per year. In very wet years, however, it may experience large displacement episodes (up to $1 \mathrm{~cm} \mathrm{day}^{-1}$ ) which are "too fast" for the C-band ERS DInSAR capabilities with a repeat cycle of 35 days. On the contrary, in dry years the landslide may stop completely in the intermediate unit and reduce significantly the rate of displacement in the lowest unit. In order to guarantee that CR could measure displacements under any circumstance, CR network was deployed in both units.

4. Installation of CRs. Finally, particular attention must be paid to the correct orientation, both planimetric (yellow arrow in Fig. 3a) and vertical (green arrow in Fig. 3a), of the CRs that should receive and effectively reflect the signal from the SAR sensor (Ge et al., 2001). For the planimetric orientation, CRs needs to be oriented perpendicular to the trajectory of the satellite, while the vertical position should be related to the incidence angle of the SAR acquisition (Fig. 3). In order to reach the maximum response, the radar LOS and the CR symmetry axis must overlap (Xia et al., 2004). In this regard, as a rule of thumb, the tolerance, both planimetric and vertical, is in the range of $\pm 5^{\circ}$. In addition, it is important to choose appropriate locations for the CRs and adequate systems to fix the CRs to the ground over long observation periods, e.g., several years for very slow landslides. Three different platforms including metal boxes, rocks, and the land itself (see Fig. 2) were used in this campaign.

\subsection{DInSAR with corner reflectors: data analysis procedure}

This section describes the DInSAR data analysis required to estimate displacements on a set of CRs. Considering a pair of CRs and an interferogram, the basic input observation of such an analysis is given by the interferometric phase difference computed over the CRs:

$\Delta \Phi^{k}\left(\mathrm{CR}_{i}, \mathrm{CR}_{j}\right)=\Phi^{k}\left(\mathrm{CR}_{i}\right)-\Phi^{k}\left(\mathrm{CR}_{j}\right)$

$=\Delta \Phi_{\text {Defo }}^{k}+\Delta \Phi_{\text {Topo }}^{k}+\Delta \Phi_{\text {Atm }}^{k}+\Delta \Phi_{\text {Orbit }}^{k}+\Delta \Phi_{\text {Noise }}^{k}$

where $\Delta \Phi^{k}\left(\mathrm{CR}_{i}, \mathrm{CR}_{j}\right)$ is the phase difference between $\mathrm{CR}_{i}$ and $\mathrm{CR}_{j}$, and $k$ indicates the interferogram number; $\Phi^{k}\left(\mathrm{CR}_{i}\right)$ is the phase of $\mathrm{CR}_{i} ; \Phi^{k}\left(\mathrm{CR}_{j}\right)$ is the phase of $\mathrm{CR}_{j} ; \Delta \Phi_{\text {Defo }}^{k}$ is the phase component due to deformation; $\Delta \Phi_{\text {Topo }}^{k}$ is the topographic phase component; $\Delta \Phi_{\text {Atmo }}^{k}$ is the atmospheric contribution; $\Delta \Phi_{\text {Orbit }}^{k}$ is the term due to orbital errors; and $\Delta \Phi_{\text {Noise }}^{k}$ is the phase noise (Hanssen, 2001; Crosetto et al., 2005).

The above equation relates the main observation $\Delta \Phi^{k}$ to five different phase components. A detailed phase analysis involving the steps briefly discussed below is required in order to properly estimate the deformation.

1. Selection of the reference pixel. The first step is the selection of a reference pixel to estimate the deformation. This pixel, which can be a CR or any other coherent pixel, is usually chosen in a stable area located in the vicinity of the deformation area of interest. All other pixel phases are then referred to it and, as a consequence, all the estimated deformations will be relative to it. For each interferogram, this is done by:

$\Delta \Phi_{\text {new }}^{k}($ col,lin $)=\Delta \Phi_{\text {old }}^{k}($ col, lin $)-\Delta \Phi_{\text {old }}^{k}($ col_ref, lin_ref $)$

where $\Delta \Phi_{\text {new }}^{k}(\mathrm{col}$, lin $)$ and $\Delta \Phi_{\text {old }}^{k}($ col,lin $)$ are the new (referenced) and the old (original) interferometric phases of a generic pixel (col,lin), while $\Delta \Phi_{\text {old }}^{k}$ (col_ref,lin_ref) is the original phase of the reference pixel. If the reference point coincides with a CR 


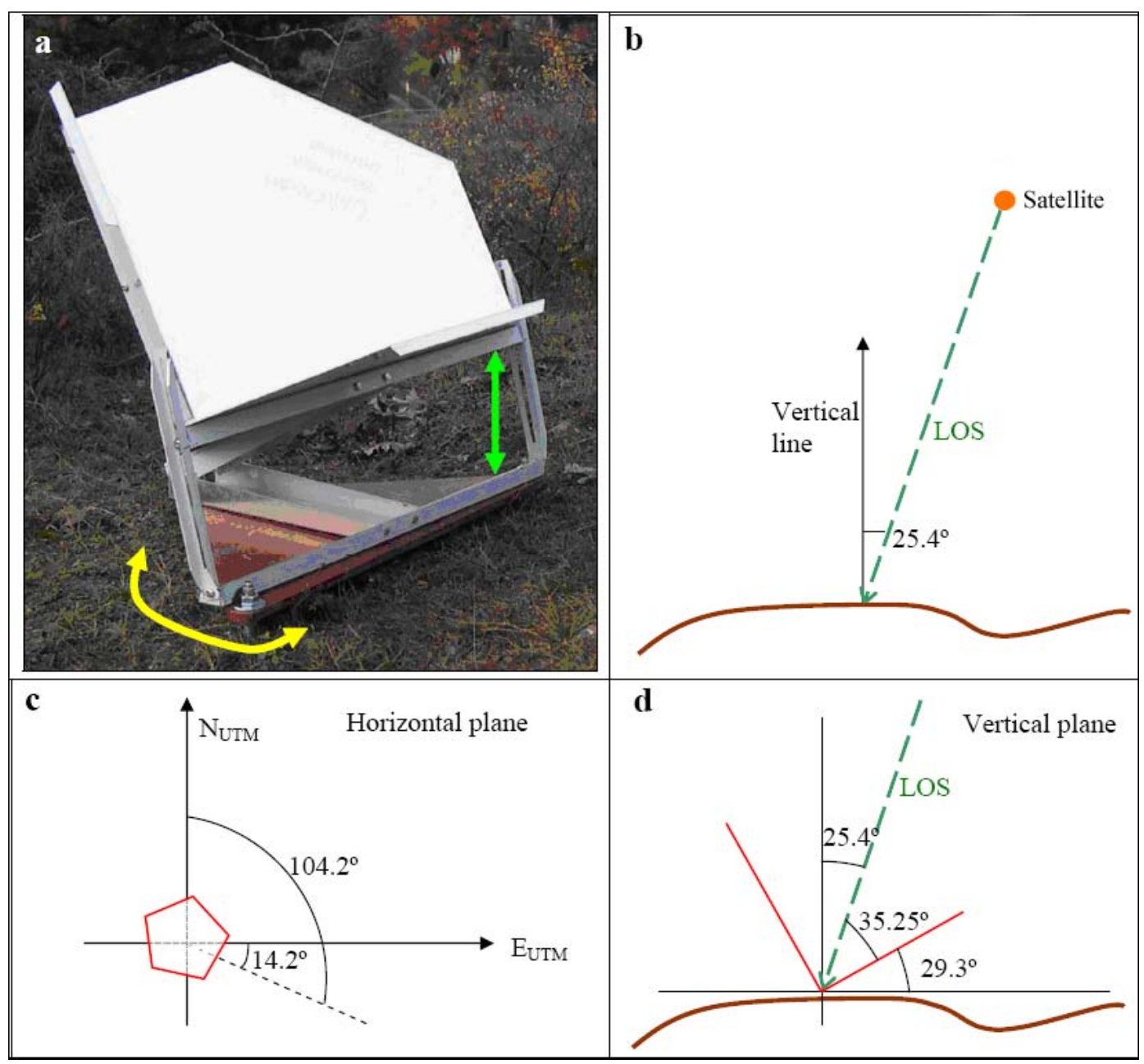

Fig. 3. Geometry of the Corner Reflectors (CRs): (a) The CRs need to be oriented perpendicular to the trajectory of the satellite for the planimetric orientation (yellow arrow). The vertical position (green arrow) should be related to the incidence angle of the SAR acquisition; (b) geometry of the acquisition; (c) planimetric geometry; (d) geometry in the vertical plane.

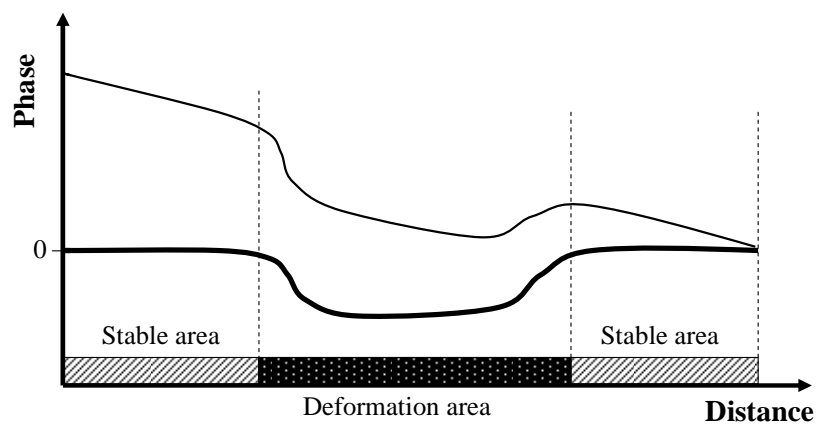

Fig. 4. Scheme of the atmospheric and orbital phase de-trending achieved by zeroing the phase over the stable areas. The original phase profile, affected by a trend, is depicted with a thin line, while the de-trended one is shown in bold.
$\left(\mathrm{CR}_{R}\right)$, the following equation is obtained using the notation of Eq. (2):

$$
\begin{aligned}
& \Delta \Phi^{k}\left(\mathrm{CR}_{i}, \mathrm{CR}_{R}\right)=\Phi^{k}\left(\mathrm{CR}_{i}\right)-\Phi^{k}\left(\mathrm{CR}_{R}\right)=\Delta \Phi_{\text {Defo_Ri }}^{k} \\
& +\Delta \Phi_{\text {Topo_Ri }}^{k}+\Delta \Phi_{\mathrm{Atm} \_R i}^{k}+\Delta \Phi_{\text {Orbit_Ri }}^{k}+\Delta \Phi_{\text {Noise_Ri }}^{k}
\end{aligned}
$$

In this case all the phase components are relative to the reference point $\mathrm{CR}_{R}$. This notation will be used hereafter. In the Vallcebre case the reference pixel was CR2, see Table 1 .

2. Phase noise, atmospheric and orbital phase components. In the phase analysis, the $\Delta \Phi_{\text {Noise_Ri }}^{k}$ component is usually assumed to be negligible. This is generally the case if the CRs used are maintained in good conditions. In contrast, if this is not the case, this component will directly affect the deformation estimate. The $\Delta \Phi_{\text {Atm_Ri }}^{k}$ and $\Delta \Phi_{\text {Orbit_Ri }}^{k}$ components usually have minor effects 
Table 1. Analysis of the six interferometric phases of seven CRs of the Vallcebre landslide. The columns contain: the interferograms number (1st); the master and slave image, with the corresponding acquisition date (2nd and 3rd); the period covered by each interferogram (4th); the perpendicular baseline (5th); and the original interferometric phases, highlighted in italic, and the unwrapped ones, in bold (6th to 12th).

\begin{tabular}{llllllllllll}
\hline Interf. (\#) & $\begin{array}{l}\text { Master image } \\
\text { date }(\mathrm{dd} / \mathrm{mm} / \mathrm{yy})\end{array}$ & $\begin{array}{l}\text { Slave image } \\
\text { date }(\mathrm{dd} / \mathrm{mm} / \mathrm{yy})\end{array}$ & $\begin{array}{l}\text { Dt } \\
(\text { days })\end{array}$ & $\begin{array}{l}B_{\text {perp }} \\
\text { (meters) }\end{array}$ & $\begin{array}{l}\text { CR_1 } \\
(\mathrm{rad})\end{array}$ & $\begin{array}{l}\text { CR_2 } \\
(\mathrm{rad})\end{array}$ & $\begin{array}{l}\text { CR_3 } \\
(\mathrm{rad})\end{array}$ & $\begin{array}{l}\text { CR_4 } \\
(\mathrm{rad})\end{array}$ & $\begin{array}{l}\text { CR_5 } \\
(\mathrm{rad})\end{array}$ & $\begin{array}{l}\text { CR_6 } \\
(\mathrm{rad})\end{array}$ & $\begin{array}{l}\text { CR_7 } \\
(\mathrm{rad})\end{array}$ \\
\hline 12 & $29 / 12 / 2006$ & $09 / 03 / 2007$ & 70 & -10.33 & 0.34 & 0.00 & 0.76 & 0.62 & 1.13 & 0.89 & 0.15 \\
\hline 13 & $29 / 12 / 2006$ & $18 / 05 / 2007$ & 140 & 561.50 & 1.85 & 0.00 & 0.84 & 2.81 & 1.31 & 0.62 & -0.10 \\
\hline 14 & $29 / 12 / 2006$ & $22 / 06 / 2007$ & 175 & 415.65 & -1.18 & 0.00 & 2.27 & -1.38 & 3.10 & 2.39 & 0.86 \\
& & & & $\mathbf{5 . 1 0}$ & & & $\mathbf{4 . 9 0}$ & & \\
\hline 23 & $09 / 03 / 2007$ & $18 / 05 / 2007$ & 70 & 571.91 & 1.53 & 0.00 & -0.12 & 2.12 & 0.07 & -0.39 & -0.44 \\
\hline 24 & $09 / 03 / 2007$ & $22 / 06 / 2007$ & 105 & 426.10 & -1.50 & 0.00 & 1.36 & -2.05 & 1.90 & 1.43 & 0.57 \\
& & & & & $\mathbf{4 . 7 8}$ & & & $\mathbf{4 . 2 3}$ & & \\
\hline 34 & $18 / 05 / 2007$ & $22 / 06 / 2007$ & 35 & -145.95 & 3.25 & 0.00 & 1.43 & 2.27 & 1.90 & 1.90 & 1.03 \\
\hline
\end{tabular}

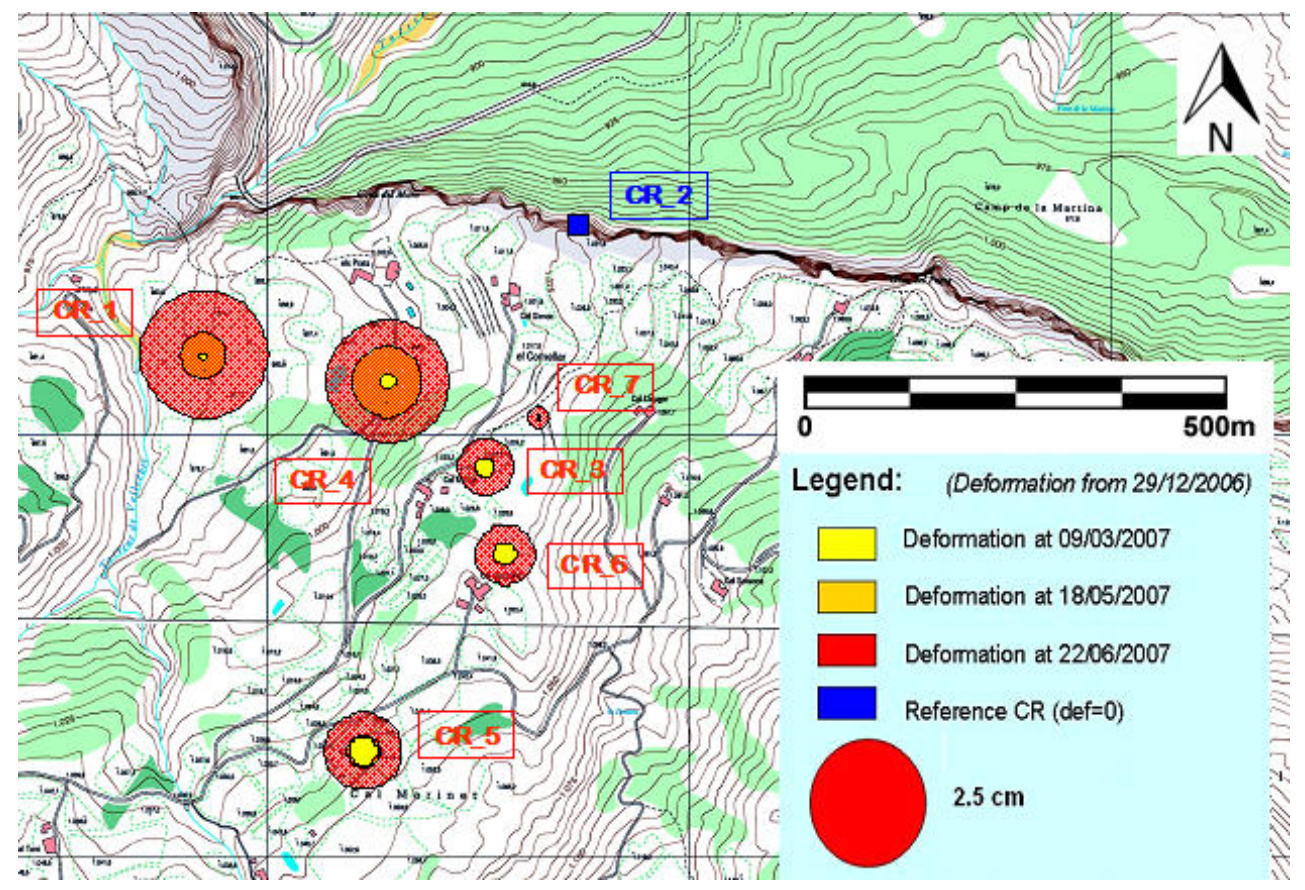

Fig. 5. Map of Vallcebre showing the location of the Corner Reflectors (CRs) and the estimated Line-Of-Sight (LOS) cumulative displacements since the date of acquisition of the first image.

on CR networks that cover limited extensions. However, if the effects need to be removed, it can be done by de-trending the phases, see Fig. 4 . This operation requires the availability of stable areas in the vicinity of the CR network. In fact, the atmospheric and orbital phase components are estimated over the stable areas and then interpolated/extrapolated over the deformation area at hand.

3. Topographic phase component. The analysis of the $\Delta \Phi_{\text {Topo_Ri }}^{k}$ is important because it can affect the deformation estimate of each CR in a different way. If an accurate Digital Terrain Model (DTM) is used in the interferogram generation and the CRs are located on the ground, the $\Delta \Phi_{\text {Topo_Ri }}^{k}$ should be, in principle, negligible. However, this component is modulated by the perpendicular baseline $\left(B_{\text {perp }}\right)$ of each interferogram. For example, a CR located at $1 \mathrm{~m}$ height with respect to the ground (i.e., with respect to the DTM) generates a $\Phi_{\text {Topo }}=2.2^{\circ}$ with $B_{\text {perp }}=50 \mathrm{~m}$, and a $\Phi_{\text {Topo }}=$ $-17.2^{\circ}$ with $B_{\text {perp }}=-400 \mathrm{~m}$. For this reason, it is useful to check if $\Delta \Phi^{k}\left(\mathrm{CR}_{i}, \mathrm{CR}_{R}\right)$ is correlated with the set of $B_{\text {perp }}^{k}$, with $k=1, \ldots, M$, where $M$ is the number of analysed interferograms. If this correlation exists, $\Delta \Phi^{k}\left(\mathrm{CR}_{i}, \mathrm{CR}_{R}\right)$ will be probably dominated by 
the topographic component, at least for all the interferograms characterised by large $B_{\text {perp }}$, and this issue can directly affect the estimation of deformation. In contrast, if the correlation between $\Delta \Phi^{k}\left(\mathrm{CR}_{i}, \mathrm{CR}_{R}\right)$ and $B_{\text {perp }}^{k}$ is null or very weak, it indicates that the $\Delta \Phi_{\text {Topo_Ri }}^{k}$ is negligible. For instance, this occurs for the phases of the CRs shown in Table 1.

4. Deformation phase component and phase unwrapping. According to Eq. (4), if all the phase components analysed in previous steps are negligible, $\Delta \Phi^{k}\left(\mathrm{CR}_{i}, \mathrm{CR}_{R}\right)$ should basically contain $\Delta \Phi_{\text {Defo_Ri }}^{k}$ (relative to the reference). However, one of the major problems of the DInSAR technique is that $\Delta \Phi^{k}\left(\mathrm{CR}_{i}, \mathrm{CR}_{R}\right)$ is only known module $2 \pi$, i.e., to retrieve the full value of this phase $\Delta \Phi_{\text {full }}^{k}\left(\mathrm{CR}_{i}, \mathrm{CR}_{R}\right)$ an unknown integer number $N$ of phase cycles $(2 \pi)$ needs to be added:

$\Delta \Phi_{\text {full }}^{k}\left(\mathrm{CR}_{i}, \mathrm{CR}_{R}\right)=\Delta \Phi^{k}\left(\mathrm{CR}_{i}, \mathrm{CR}_{R}\right)+2 \cdot N \cdot \pi$

The estimation of the term $2 \cdot N \cdot \pi$ is called phase unwrapping. It is worth noting that the above equation has infinite solutions, i.e., from the mathematical point of view, phase unwrapping is an ill-posed problem. If deformations are large enough to induce several phase cycles, it is almost impossible to estimate them correctly. However, if they cause a $\Delta \Phi_{\text {Topo } R i}^{k}$ that is a fraction of the cycle in most of the interferograms, phase unwrapping can be performed by implicitly assuming that $N=0$ in most of the interferograms and by checking the temporal consistency of redundant interferograms. The example of Table 1 can be used to illustrate this issue, where six interferograms were generated from four images. Naming the images from 1 to 4 , the interferograms 12, 13, 14, 23, 24 and 34 were generated. Any linear combination of phases can be used to check the phase consistency, for example:

$$
\begin{aligned}
& \Delta \Phi_{\text {full }}^{14}\left(\mathrm{CR}_{i}, \mathrm{CR}_{R}\right)=\Delta \Phi_{\text {full }}^{12}\left(\mathrm{CR}_{i}, \mathrm{CR}_{R}\right) \\
& +\Delta \Phi_{\text {full }}^{23}\left(\mathrm{CR}_{i}, \mathrm{CR}_{R}\right)+\Delta \Phi_{\text {full }}^{34}\left(\mathrm{CR}_{i}, \mathrm{CR}_{R}\right)
\end{aligned}
$$

If this equation is not satisfied, one or more phase cycles must be added until it is. For instance, this happens in the first column of Table 1 for the phases $14=13+34$ highlighted in italics:

$-1.18 \neq 1.85+3.25[\mathrm{rad}]$

This equation is satisfied by adding a phase cycle to the left-hand term (value highlighted in bold in Table 1):

$-1.18+6.28=5.10=1.85+3.25[\mathrm{rad}]$

It is worth noting that the addition of a phase cycle is just one of the infinite possible solutions of the above equation. By choosing this one we assume that the shorter interferograms (those that encompass a shorter time interval) have $N=0$ and we consider that the displacements of the landslide are expected to be downward. In fact, $\Delta \Phi_{\text {full }}^{14}\left(\mathrm{CR}_{i}, \mathrm{CR}_{R}\right)=-1.18 \mathrm{rad}$ would indicate an upward displacement.

5. Deformation computation. The deformation phase components have to be transformed into displacements. The first step is to transform them into the radar LOS displacements:

$\operatorname{Displ}_{\mathrm{LOSi}}^{k}\left(\mathrm{CR}_{i}, \mathrm{CR}_{R}\right)=\Delta \Phi_{\text {Defo_Ri }}^{k} \cdot \frac{\lambda}{4 \cdot \pi}$

If the geometry of displacements is known, the $\operatorname{Displ}_{\mathrm{LOSi}}^{k}$ can be projected to their known direction. In the next section, the Displ ${ }_{\mathrm{LOSi}}^{k}$ of the Vallcebre landslide were projected to the maximum local slope.

\section{DInSAR results}

A first analysis was carried out using four descending Envisat SAR images, spanning seven months and acquired the days 29/12/2006, 9/3/2007, 18/5/2007 and 22/7/2007. From the four images six interferograms were generated and analysed following the procedure described in the previous section, see Table 1. Figure 5 shows a map of Vallcebre that indicates the location of the CRs, including the reference CR2 (stable ground), and the estimated LOS displacements occurred since the date of acquisition of the first image, 29 December 2006. The CRs basically show several patterns of movement: CR7 experiences a small accumulated displacement (below $0.5 \mathrm{~cm}$ ); CR3, CR5 and CR6 have maximum LOS displacements between 1 and $1.5 \mathrm{~cm}$; and CR 1 and CR4, which are located in the most active part of the landslide (lowest unit), show maximum LOS displacements between 2 and $2.5 \mathrm{~cm}$.

Figure 6 displays the temporal evolution of the CR displacements projected in the direction of the maximum local slope angle together with the precipitations recorded in the analysed period. It can be observed that the displacements were small between the end of December 2006 and the beginning of March 2007, while for CR1 and CR4 there is a substantial increase of displacements in March and April associated to abundant rainfall.

Even though a homogeneous behaviour has been traditionally assumed for the landslide units in Vallcebre, the results of the CRs suggest a more complex one. CRs located in the intermediate unit (CR3, CR5, CR6 and CR7) evidence the presence of landslide subunits with slightly different rates of displacement. CR7 located close to the northern boundary of the landslide shows displacements significantly smaller than the other CRs. In the southern edge, CR5 is placed at the head of a local failure which is moving faster than the rest of the unit. Figures 5 and 6 also show a different temporal 


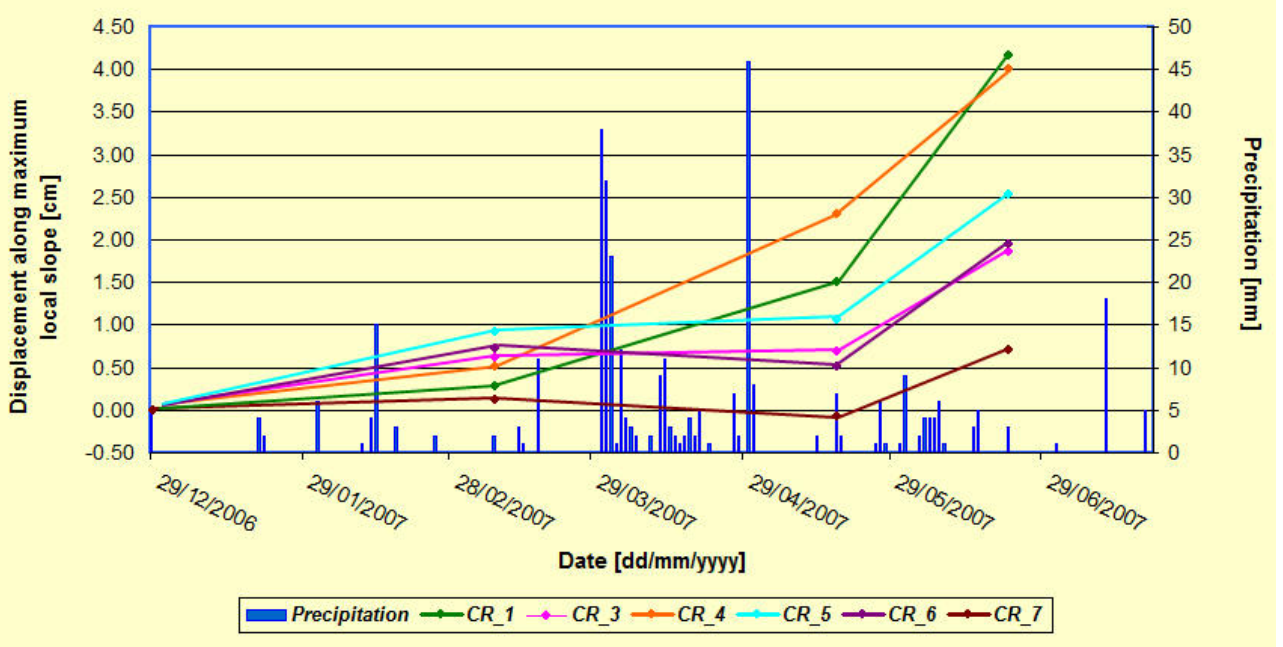

Fig. 6. Time series showing the temporal evolution of the Corner Reflectors (CRs) displacements projected in the direction of the maximum local slope angle and precipitations recorded during the analysed period.

behaviour between the main landslide units. In the first analysed period (until March 2007), displacements at the intermediate unit are larger than those in the lowest one. Between March and May 2007, the situation is reversed and movement at CR1 and CR4 (lowest unit) accelerates significantly while those of the intermediate unit decrease. Even though the increase of pore water pressures has been claimed as the main cause for the sudden increase of the landslide displacements (Corominas et al., 2005), a similar response can be obtained by considering the erosion of the landslide foot by the Vallcebre torrent (Ferrari et al., 2011). As high discharge of the Vallcebre torrent is associated only with high-intensity rainfall events such as the observed between March and May 2007 (Fig. 6), this suggests erosion is the predominant factor in the analysed events. This may also explain the fact that displacements decrease from the landslide foot towards the landslide head (Fig. 5). Between May and the end of July 2007, all CRs display similar displacement rates.

A second analysis based on the same procedure described above was performed using 10 descending Envisat SAR images and 21 interferograms, covering the period 22/2/2008 to $2 / 1 / 2009$. The results of this second analysis are similar to those of the first one. Figure 7 shows two displacement time series of CR4, projected in the direction of maximum local slope angle. They are useful to illustrate the problem of phase unwrapping. The continuous blue line represents one phase unwrapping solution, which has an accumulated displacement of $6.86 \mathrm{~cm}$ and which shows, between April and June 2008, an upward displacement of $1.07 \mathrm{~cm}$. Considering the kinematics of the landslide, this type of movement can be considered very unlikely. For this reason, a second solution was chosen, depicted with a dashed line and which shows an accumulated displacement of $11.95 \mathrm{~cm}$ in 11 months. The same figure shows the displacement measured by the wire ex- tensometer S5, which is located relatively close to CR4 (the $\mathrm{S} 5$ to $\mathrm{CR} 4$ distance is $84 \mathrm{~m}$ ). The extensometer S-5 is located in the contact (graben) between the intermediate and the lowest units and, given the distance between these two points, it prevents a rigorous validation of the CR4 estimate; however, it is interesting to compare the time series of CR4 and S5. They display a quite similar temporal evolution, which include a strong deformation gradient between June and July, followed by a stationary period until September and a second, less strong deformation gradient. However, CR4 measures quite stronger deformations: the accumulated displacements from DInSAR (CR4) is $11.95 \mathrm{~cm}$ while from the extensometer (S5) is $7.24 \mathrm{~cm}$. This seems to be mainly due to the 84-m distance between these points: they have different deformation magnitudes.

\section{Discussion and conclusions}

This paper mainly focuses on the discussion of the technical aspects of CR-based DInSAR monitoring. Firstly, the technical and logistic aspects related to the use of CRs have been addressed. A detailed description of the design of the CR network to properly cover a given landslide has been provided, discussing the atmospheric effects and the expected kinematic characteristics of the landslide at hand, which both limit the distance between neighbouring CRs. Secondly, the full DInSAR data analysis procedure required to derive deformation estimates from the interferometric phases has been described. The goal of this section was to provide the main concepts to properly understand and interpret the DInSAR deformation estimates. A case study of CR-based DInSAR monitoring concerning the Vallcebre landslide (Eastern Pyrenees, Spain) has been described. Two different periods have been analysed, using 4 and 10 Envisat SAR images, 


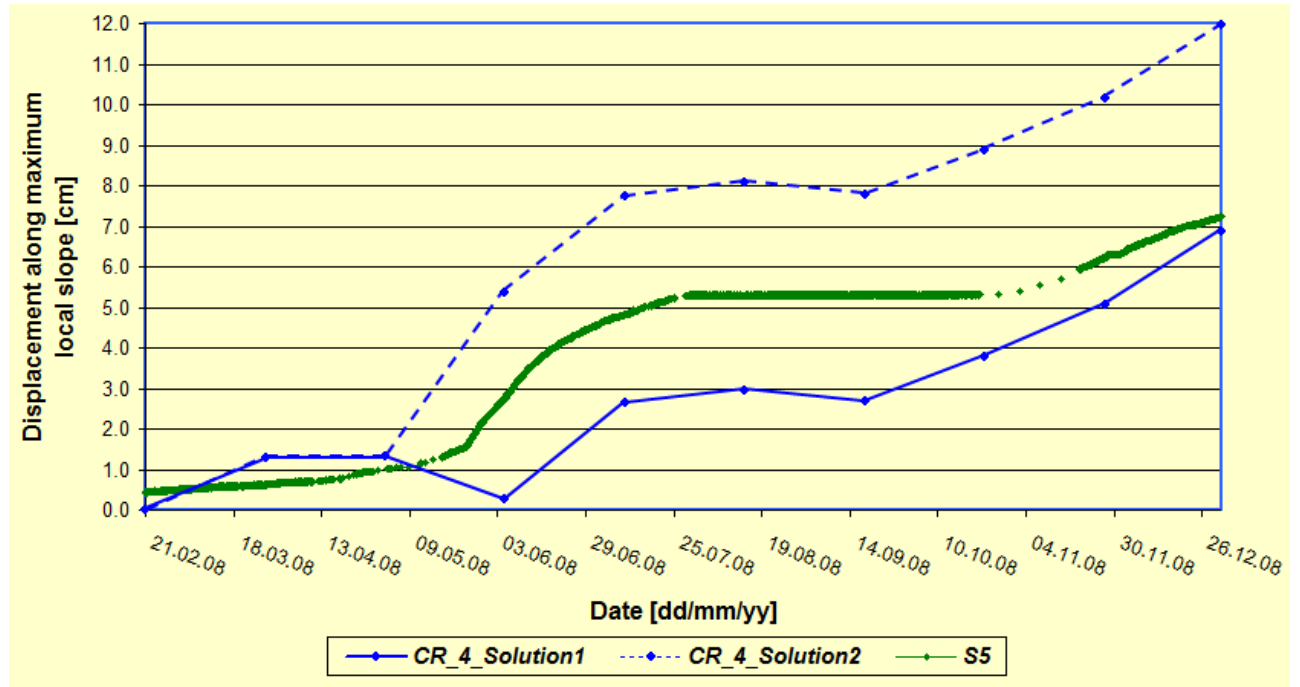

Fig. 7. Displacement time series estimated with DInSAR over one Corner Reflector (CR4), projected in the direction of maximum local slope, and measured by the extensometer S5, located at a distance of $84 \mathrm{~m}$ from CR4.

respectively. Both analyses have provided interesting results to monitor the kinematics of different parts of the landslide unit over time. It was possible to compare the results of one of the CRs of the second analysis, CR4, with the results from an extensometer located at a distance of $84 \mathrm{~m}$. The distribution of the CRs has completed the existing monitoring network and has allowed obtaining a more representative spatial distribution of the landslide displacements. The latter have shown that the landslide is less homogeneous that previously thought and that particular movement patterns may be found within the main landslide units.

Several technical aspects related to the CR-based DInSAR monitoring of the Vallcebre landslide are briefly discussed below.

- It is interesting to know whether CR-based DInSAR provides additional information that could not be discovered by any other mean about the Vallcebre landslide. There is a wide range of alternative monitoring techniques with different performances and costs. CR-based DInSAR specifically provides two key advantages to landslide monitoring: a fully remote and automatic data acquisition (once the CRs are installed and neglecting CR maintenance tasks) and a high sensitivity to deformations. Both advantages are relevant to the Vallcebre case study.

- DInSAR complements well with in-hole wire extensometers. The latter measures landslide displacements with millimetre accuracy, similar to that of the DInSAR. The main advantage of the extensometers is that they provide a continuous measurement of the displacements which can be directly used for the analysis of the triggers (i.e., rainfall, groundwater fluctuations). The sim- ilar evolution of the displacements observed for some CRs and extensometers suggest that DInSAR displacement rates can be calibrated with the extensometers' readings in a way similar to the GPS measurements (Gili et al., 2000). CRs are significantly cheaper than the wire extensometers, which are installed in drilled boreholes and require both recording and data storage/transmission equipment as well as maintenance for replacing the components that went out of order or vandalised.

- Related to the two previous points, it is worth commenting the main differences of CR-based DInSAR and GPS for landslide monitoring. DInSAR is usually more sensitive to small displacements (order of one millimetre) than GPS: this is especially important to monitor very slow deformation phenomena. DInSAR is a remotesensing technique, while GPS usually requires in-situ campaigns. On the other hand, GPS provides unambiguous 3D deformation displacements, while DInSAR provides only LOS displacements.

- It is worth emphasising that, if feasible, a DInSAR analysis without CRs is always preferred to a CR-based DInSAR. In fact, the latter one needs the in-situ installation of the CRs and cannot be used to perform historical deformation studies based on archived SAR imagery, because only the SAR images acquired after the CR installation can be used. To partially mitigate the limitation of using CRs, it would be good to merge them together with the natural reflectors available in a given site. The use of very high resolution SAR imagery should substantially increase the availability of natural reflectors, thus, potentially decreasing the need of CRs. 
Acknowledgements. This work was partially supported by the Working Community of the Pyrenees through the project SAXA (2010 CTP 00048) and funded by the FP7 project SAFELAND (Grant Agreement 226479) and the DGI-MCYT project MODEVALL (CGL2005-05282).

Edited by: F. Catani

Reviewed by: T. Strozzi and M.-H. Derron

\section{References}

Berardino, P., Fornaro, G., Lanari, R., and Sansosti, E.: A new algorithm for surface deformation monitoring based on small baseline differential SAR interferograms, IEEE T. Geosci. Remote Sens., 40, 2375-2383, 2002.

Cigna, F., Bianchini, S., and Casagli, N.: How to assess landslide activity and intensity with Persistent Scatterer Interferometry (PSI): the PSI-based matrix approach, Landslides, 1-17, doi:10.1007/s10346-012-0335-7, 2012.

Colesanti, C., Ferretti, A., Prati, C., and Rocca, F.: Monitoring landslides and tectonic motions with the Permanent Scatterers Technique, Eng. Geol., 68, 3-14, 2003.

Colesanti, C. and Wasowski, J.: Investigating landslides with spaceborne Synthetic Aperture Radar (SAR) Interferometry, Eng. Geol., 88, 173-199, 2006.

Corominas, J., Moya, J., Lloret, A., Gili, J. A., Angeli, M. G., Pasuto, A., and Silvano, S.: Measurement of landslide displacements using a wire extensometer, Eng. Geol., 55, 149-166, 2000.

Corominas, J., Moya, J., Ledesma, A., Lloret, A., and Gili, J. A.: Prediction of ground displacements and velocities from groundwater level changes at the Vallcebre landslide (Eastern Pyrenees, Spain), Landslides, 2, 83-96, 2005.

Crosetto, M., Tscherning, C. C., Crippa, B., and Castillo, M.: Subsidence monitoring using SAR interferometry: reduction of the atmospheric effects using stochastic filtering, Geophys. Res. Lett., 29, 26-29, doi:10.1029/2001GL013544, 2002.

Crosetto, M., Crippa, B., Biescas, E., Monserrat, O., Agudo, M., and Fernandez, P.: Land deformation measurement using SAR interferometry: state-of-the-art, Photogrammetrie Fernerkundung Geoinformation, 6, 497-510, 2005.

Crosetto, M., Biescas, E., Duro, J., Closa, J., and Arnaud, A.: Quality assessment of advanced interferometric products based on time series of ERS and Envisat SAR data, Photogr. Eng. Remote Sens., 74, 443-450, 2008.

Doerry, A. W.: Reflectors for SAR Performance Testing, SANDIA Report, SAND2008-0396, http://infoserve.sandia.gov/sand /2008/080396.pdf, (last access 27 April 2010), 2008.

Farina, P., Colombo, D., Fumagalli, A., Marks, F., and Moretti, S.: Permanent scatterers for landslide investigations: outcomes from the ESA-SLAM project, Eng. Geol., 88, 200-217, 2006.

Ferrari, A., Ledesma, A., González, D. A., and Corominas, J.: Effects of the foot evolution on the behaviour of slow-moving landslides, Eng. Geol., 117, 217-228, 2011.

Ferretti, A., Prati, C., and Rocca, F.: Nonlinear subsidence rate estimation using permanent scatterers in differential SAR interferometry, IEEE T. Geosci. Remote Sens., 38, 2202-2212, 2000.

Ferretti, A., Prati, C., and Rocca, F.: Permanent scatterers in SAR interferometry, IEEE T. Geosci. Remote Sens., 39, 8-20, 2001.
Ferretti, A., Savio, G., Barzaghi, R., Borghi, A., Musazzi, S., Novali, F., Prati, C., and Rocca, F.: Submillimeter Accuracy of InSAR Time Series: Experimental Validation, IEEE T. Geosci. Remote Sens., 45, 1142-1153, 2007.

García-Davalillo, J., Herrera, G., Notti, D., Strozzi, T., and ÁlvarezFernández, I.: DInSAR analysis of ALOS PALSAR images for the assessment of very slow landslides: the Tena Valley case study, Landslides, doi:10.1007/s10346-012-0379-8, 2013.

Ge, L., Rizos, C., Han, S., and Zebker, H.: Mining subsidence monitoring using the combined InSAR and GPS approach, Proceedings of the 10th FIG International Symposium on Deformation Measurements, Orange, CA, pp. 1-10, 2001.

Gili, J. A., Corominas, J., and Rius, J.: Using Global Positioning System techniques in landslide monitoring, Eng. Geol., 55, 167192, 2000.

Hanssen, R.: Radar interferometry, Kluwer Academic Publishers, Dordrecht (The Netherlands), 2001.

Herrera, G., Notti, D., García-Davalillo, J. C., Mora, O., Cooksley, G., Sánchez, M., Arnaud, A., and Crosetto, M.: Landslides analysis with C- and X-band satellite SAR data: the Portalet landslide area, Landslides, 7, 1-12, 2010.

Hilley, G. E., Burgmann, R., Ferretti, A., Novali, F., and Rocca, F.: Dynamics of slow-moving landslides from Permanent Scatterer analysis, Science, 304 (5679), 1952-1955, 2004.

Hooper, A., Zebker, H., Segall, P., and Kampes, B.: A new method for measuring deformation on volcanoes and other natural terrains using InSAR Persistent Scatterers, Geophys. Res. Lett., 31, L23611, doi:10.1029/2004GL021737, 2004.

Meisina, C., Zucca, F., Fossati, D., Ceriani, M., and Allievi, J.: Ground deformation monitoring by using the permanent scatterers technique: the example of the Oltrepo Pavese (Lombardia, Italy), Eng. Geol., 88, 240-259, 2006.

Monserrat, O., Moya, J., Luzi, G., Crosetto, M., Gili, J. A., and Corominas, J.: Non interferometric GBSAR measurement, Application to the Vallcebre Landslide (Eastern Pyrenees, Spain, accepted, Nat. Hazards Earth Syst. Sci., 2013.

Rosen, P. A., Hensley, S., Joughin, I. R., Li, F. K., Madsen, S. N., Rodriguez, E., and Goldstein, R. M.: Synthetic Aperture Radar Interferometry, Proc. the IEEE, 88, 333-382, 2000.

Strozzi, T., Farina, P., Corsini, A., Ambrosi, C., Thüring, M., Zilger, J., Wiesmann, A., Wegmüller, U., and Werner, C.: Survey and monitoring of landslide displacements by means of L-band satellite SAR interferometry, Landslides, 2, 193-201, doi:10.1007/s10346-005-0003-2, 2005.

Strozzi, T., Delaloye, R., Kääb, A., Ambrosi, C., Perruchoud, E., and Wegmüller, U.: Combined observations of rock mass movements using satellite SAR interferometry, differential GPS, airborne digital photogrammetry, and airborne photography interpretation, J. Geophys. Res., 115, F01014, doi:10.1029/2009JF001311, 2010.

Xia, Y., Kaufmann, H., and Guo, X. F.: Landslide Monitoring in the Three Gorges Area Using D-INSAR and Corner Reflectors, Photogr. Eng. Remote Sens., 70, 1167-1172, 2004. 